\title{
Circulating levels of vascular endothelial markers in obstructive sleep apnoea syndrome. Effects of nasal continuous positive airway pressure
}

\author{
Carlos Zamarrón ${ }^{1}$, Alberto Riveiro², Francisco Gude ${ }^{3}$
}

1Pulmonary Division, Hospital Clínico Universitario, Santiago de Compostela, Spain 2Division of Respiratory Medicine, Department of Biochemistry, Hospital Clínico Universitario, Santiago de Compostela, Spain

${ }^{3}$ Clinical Epidemiological Research Unit, Hospital Clínico Universitario, Santiago de Compostela, Spain

Submitted: 14 March 2011

Accepted: 19 June 2011

Arch Med Sci 2011; 7, 6: 1023-1028

DOI: $10.5114 /$ AOMS.2011.26615

Copyright (๐) 2011 Termedia \& Banach

\section{Abstract}

Introduction: Obstructive sleep apnoea syndrome (OSAS) is an important risk factor in cardiovascular disorders. Although the exact mechanism remains to be elucidated, the endothelial dysfunction process seems to be implicated.

Material and methods: In order to test this hypothesis, blood circulating levels of endothelial markers were measured at baseline and 1 year after treatment with continuous positive airway pressure (CPAP). We studied 37 males using polysomnography: 20 subjects with OSAS and a 17-subject control group. An OSAS-validated sleep questionnaire covering the most important cardiovascular risk factors was applied to all subjects. Furthermore, patients received a complete general physical examination and biochemistry test with lipid profile. The specific markers measured were intercellular cell adhesion molecule-1 (ICAM-1), E-selectin, endothelin-1, von Willebrand factor (vWF) and plasminogen activator inhibitor-1 (PAI-1).

Results: Obstructive sleep apnoea syndrome patients presented higher circulating levels of ICAM-1, endothelin-1 and PAI-1 than the control group. On the other hand, no differences were found in E-selectin and VWF. After 1 year of CPAP treatment, there was a significant decrease in circulating levels of ICAM-1 and PAI-1. On the other hand, no differences were found in endothelin-1, E-selectin and vWF.

Conclusions: Obstructive sleep apnoea syndrome is associated with elevated levels of ICAM- 1 and PAI- 1 and these levels normalize after treatment with CPAP.

Key words: obstructive sleep apnoea syndrome, intercellular cell adhesion molecule-1, E-selectin, endothelin-1, plasminogen activator inhibitor-1.

\section{Introduction}

Obstructive sleep apnoea syndrome (OSAS) is a respiratory disorder characterized by recurrent airflow obstruction caused by total or partial collapse of the upper airway. Obstructive sleep apnoea syndrome is a common disorder [1], with important consequences such as deterioration of quality of life [2] and more frequent automobile accidents [3]. Obstructive sleep apnoea syndrome has been associated with hypertension and cardiovascular disease [4] and a number of studies have shown that this car-

\author{
Corresponding author: \\ Carlos Zamarrón MD \\ Servicio de Neumología \\ Hospital Clínico Universitario \\ de Santiago \\ C/ Choupana s/n \\ 15706, Santiago de Compostela \\ Spain \\ E-mail: \\ carlos.zamarron.sanz@ \\ sergas.es
}


diovascular risk decreases after continuous positive airway pressure (CPAP) treatment $[5,6]$.

Increased sympathetic activity and hypoxia associated with apnoeic episodes has been proposed as a possible mechanism to explain the association between OSAS and cardiovascular disease [7]. Continuous positive airway pressure treatment may lower cardiovascular risk by reducing sympathetic nerve activity, ambulatory blood pressure and arterial stiffness and by increasing sensitivity of the arterial baroreflex $[8,9]$.

Obstructive sleep apnoea syndrome-induced hypoxic stress increases circulating inflammatory mediators leading to cardiovascular lesions [10, 11], which in turn may lead to endothelial dysfunction. Endothelial dysfunction is an early marker of vascular abnormality preceding clinically overt cardiovascular disease [12]. It is known that endothelial dysfunction identified in the peripheral vasculature strongly predicts coronary disease [13]. A number of studies involving OSAS patients indicate an associated endothelial dysfunction $[14,15]$ that improves after CPAP $[16,17]$.

An imbalance of the coagulation/fibrinolysis axis may also exist. Hypercoagulability resulting from increased coagulation or inhibited fibrinolysis is associated with an increased risk of atherothrombotic disease and cardiovascular disease $[18,19]$. A prothrombotic state has been associated with increased risk of coronary artery disease [20] and is a possible link between OSAS and cardiovascular disease [21]. Although most of the above-mentioned OSAS-related physiopathological consequences return to normal after CPAP treatment, the results reported in the literature have not been consistent. The reason may be that these studies do not exclude other cardiovascular risk factors and that their analysis of markers is too limited.

The aim of the present study was to measure circulating ICAM-1, E-selectin, endothelin-1, von Willebrand factor (VWF) and plasminogen activator inhibitor-1 (PAI-1) in OSAS patients before CPAP treatment at 1-year follow-up.

\section{Material and methods}

\section{Subjects}

The present study included 20 male subjects, 33 to 64 years of age (mean of $49.9 \pm 8.9$ years), with a mean apnoea-hypopnoea index (AHI) of 45.2 \pm 26.2 and body mass index (BMI) of $29.9 \pm 4.6$ $\mathrm{kg} / \mathrm{m}^{2}$, diagnosed with OSAS after performing polysomnography studies. A control group made up of 17 male subjects from the general population was also included. Exclusion criteria were previous treatment for OSAS, chronic obstructive lung disease, vascular disease, history of hypertension, diabetes mellitus, and chronic renal illness.
The Review Board on Human Studies at our institution approved the protocol, and each patient gave his or her informed consent to participate in the study.

\section{Interventions}

An OSAS-validated sleep questionnaire covering the most important cardiovascular risk factors was applied to all subjects. Furthermore, patients received a complete general physical examination, biochemistry test with lipid profile and polysomnographic tests.

Polysomnographies were carried out in our Sleep Unit usually from midnight to 8 a.m. This technique consisted of continuous monitoring using a polygraph (Ultrasom Network, Nicolet, Madison, Wi, USA) and included electroencephalogram, electrooculogram, chin electromyogram, airflow, electrocardiogram and measurement of chest wall movement. The polysomnographic register was analysed in periods of $30 \mathrm{~s}$ and during stages 1, 2, 3, 4 and REM according to standard criteria.

Apnoea was defined as the absence of airflow for more than $10 \mathrm{~s}$, and hypopnoea as 50\% reduction of respiratory flow for at least $10 \mathrm{~s}$ resulting in an arousal or a decrease of $4 \%$ in the oxygen saturation of haemoglobin

The average apnoea-hypopnoea index ( $\mathrm{AHI}$ ) was calculated in hourly samples of sleep. In this study an $\mathrm{AHI} \geq 10$ was considered as diagnostic of OSAS. If the subject had less than 3 hours of total sleep, the sleep study was repeated.

The optimal CPAP level was determined in the laboratory during the study. It was defined as the combination of the lowest pressure, lowest number of respiratory events and arousals, and the highest sleep efficiency.

\section{Endothelial markers}

Whole blood was obtained by venipuncture in all subjects between 8 a.m. and 10 a.m. after polysomnographic study.

A total of 5 endothelial dysfunction markers were measured: ICAM-1, E-selectin, endothelin-1, vWF, PAI-1. The blood samples were centrifuged at $1000 \mathrm{~g}$ for $10 \mathrm{~min}$, and serum/plasma was frozen and stored at $-20^{\circ} \mathrm{C}$.

Commercially available enzyme-linked immunosorbent assay (ELISA) methods were used to determine serum levels of ICAM-1 and soluble E-selectin (R\&D Systems, Minneapolis, USA), EDTA-plasma levels of endothelin-1 (Biomedica, Wien, Austria), and citrated plasma levels of VWf and PAI-1 (Diagnostica Stago, Asnieres, France).

The mean minimal detectable level was determined by adding two standard deviations to the mean optical density value of 20 zero standard 
replicates and calculating the corresponding concentrations.

\section{Follow-up protocol}

Serum/plasma levels of endothelial markers were measured at baseline and 1 year after CPAP treatment. Patient interviews were conducted by a study-team member who was not aware of the patient's AHI status and did not participate in any other aspects of clinical management. No interventions other than CPAP therapy were introduced at follow-up. Referring physicians were permitted to modify general medical therapy as required. All patients received standardized instructions by Sleep Center staff and by a home health care provider at the start of CPAP treatment. Patients were reviewed at the Sleep Clinic at 1, 6, and 12 months or when any problem with the CPAP device or mask fit was encountered. In addition, patients were reviewed every 2 months by a home health care provider.

\section{Continuous positive airway pressure compliance}

The total time that CPAP units were switched on was logged using the unit time clock. A home health care provider registered these compliance measures. Each time the patient was visited, the number of hours logged on the meter was recorded and the CPAP device was given a maintenance check.

\section{Continuous positive airway pressure satisfaction scale}

At 12-month follow-up, patients were asked to rank CPAP treatment on a scale from 0 ("no effect at all") to 10 ("complete relief of symptoms").

\section{Data analysis and measurements}

Continuous variables are expressed as mean \pm standard deviation, or as median (percentile 25, percentile 75). The $t$-test, two tailed for paired samples, was applied to test differences pre- and posttreatment; non-normally distributed variables were compared using Wilcoxon rank sum test for paired data. Statistical significance was accepted at $p<0.05$. All analyses were developed using the Statistical Package for Social Sciences (SPSS, version 15.0; SPSS Inc. Chicago, IL, USA).

\section{Results}

Baseline clinical characteristics of patients and control subjects were similar for age, body mass index (BMI), smoking habit and blood pressure (Table I).

After 12 months of nasal CPAP treatment, 82\% of patients reported that they had used nasal CPAP every day for more than $5 \mathrm{~h}$ per night. The CPAP titration pressure ranged from $5 \mathrm{~cm} \mathrm{H}_{2} \mathrm{O}$ to $14 \mathrm{~cm}$ $\mathrm{H}_{2} \mathrm{O}$ (mean $=7.8 \pm 1.51 \mathrm{~cm} \mathrm{H}_{2} \mathrm{O}$ ). On average, CPAP was used for $5.24 \pm 2.75 \mathrm{~h}$ per night. Patients selfreported a level of satisfaction of $7.48 \pm 1.90$ points after the CPAP treatment.

Table II describes circulating endothelial markers. Levels of ICAM-1, E-selectin and endothelin-1 were significantly elevated in OSAS patients as compared to controls. After treatment we can see a significant decrease in ICAM-1 and PAI, but not in endothelin, E-selectin, or VWF.

\section{Discussion}

The present study demonstrates that endothelial dysfunction, represented by changes in certain circulating endothelial markers, is present in OSAS. We found that treating OSAS patients with CPAP

Table I. Cardiovascular risk factors in control and OSAS groups

\begin{tabular}{|lccc|}
\hline Variable & $\begin{array}{c}\text { Control group } \\
(n=18)\end{array}$ & $\begin{array}{c}\text { OSAS group } \\
(n=20)\end{array}$ & Value of $p$ \\
\hline Age [year] & $44.1(14.2)$ & $50.1(8.9)$ & 0.12 \\
\hline Smokers, $n(\%)$ & $5(27)$ & $8(40)$ & 0.364 \\
\hline BMI [kg/m²] & $27.6(3.1)$ & $29.9(4.6)$ & 0.078 \\
\hline SBP [mmHg] & $124(7.3)$ & $128(11)$ & 0.156 \\
\hline DBP [mmHg] & $79.7(11.4)$ & $78.5(10.5)$ & 0.734 \\
\hline
\end{tabular}

$B M I$ - body mass index, SBP-systolic blood pressure, DBP - diastolic blood pressure, data are expressed as mean (SD)

Table II. Plasma levels of vascular endothelial markers in control and OSAS group at baseline and after 1 year of CPAP treatment

\begin{tabular}{|lccccc|}
\hline Variable & Control group $(n=18)$ & OSAS group $(n=20)$ & Value of $p$ & After CPAP $(n=20)$ & Value of $p$ \\
\hline ICAM-1 $[\mathrm{ng} / \mathrm{ml}]$ & $218(190,255)$ & $261(200,294)$ & 0.050 & $229(182,270)$ & 0.022 \\
\hline E-selectin $[\mathrm{ng} / \mathrm{ml}]$ & $54(45,63)$ & $66(48,90)$ & 0.143 & $72(42,93)$ & 0.234 \\
\hline Endothelin $[\mathrm{fmol} / \mathrm{ml}]$ & $0.2(0.12,0.30)$ & $0.35(0.26,0.45)$ & 0.003 & $0.35(0.26,0.40)$ & 0.722 \\
\hline VWF $[\%]$ & $76(63,91)$ & $83(65,100)$ & 0.411 & $79(65,101)$ & 0.616 \\
\hline PAI-1 $[\mathrm{ng} / \mathrm{ml}]$ & $30(18,45)$ & $52(24,72)$ & 0.027 & $37(12,53)$ & 0.020 \\
\hline
\end{tabular}

BMI - body mass index, AHI - apnoea-hypopnoea index, ICAM - intercellular adhesion molecule 1, vWF - von Willebrand factor, PAI - plasminogen activator inhibitor-1, data are medians and 25th-75th percentile ranges (within parentheses) 
reduced levels of ICAM-1 and PAI-1. On the other hand, no changes were found in endothelin, Von Willebrand factor and E-selectin.

The intact endothelium regulates vascular tone and repair capacity, maintaining proinflammatory, anti-inflammatory, and coagulation homeostasis. Endothelial dysfunction is characterised by an increase in vasoconstrictive substances, such as endothelin, and activation of adhesion molecules, such as ICAM-1 and E-selectin [22]. Alteration of these homeostatic pathways results in endothelial dysfunction before structural changes in the vasculature.

The association of endothelial function with OSAS observed in our study is consistent with other studies showing an association between OSAS and other markers of endothelial dysfunction, such as circulating levels of adhesion molecules [23], and vascular endothelial growth factor [24]. Furthermore, these changes improve after CPAP therapy [23, 24].

In a previous study, we found that OSAS patients compared to a control group had increased levels of ICAM-1, and that this could be due to OSASinduced hypoxia [25]. Low oxygen tension is a trigger for activation of polymorphonuclear neutrophils, which adhere to the endothelium. El-Solh et al. observed that both were significantly correlated with the oxygen desaturation index, thus suggesting that expression of adhesion molecules might be related to the intermittent hypoxia observed during sleep [26]. In fact, in vitro studies involving perfused cell cultures have shown that hypoxia/reoxygenation causes an increase in the levels of adhesion molecules [27].

The hypoxia, hypercapnia, and arterial pressure surges accompanying obstructive apnoeic events may serve as potent stimuli for the release of vasoactive substances and for impairment of endothelial function [28, 29].

A variety of findings support the existence of a relation between hypercoagulability, OSAS and cardiovascular disease. Firstly, patients with OSAS present higher plasma levels of several procoagulant factors such as fibrinogen [30], platelet activity [31], and PAI-1 [32, 33]. Secondly, increased D-dimer levels in untreated OSAS have been correlated with severity of nocturnal hypoxemia, characteristic of OSAS [34]. Thirdly, sleep fragmentation and sleep efficiency data have been associated with increased levels of VWF and soluble tissue factor (STF), two markers of a prothrombotic state [35].

In OSAS, surges in sympathetic nervous system activity associated with apnoeic events have also been related to anti-fibrinolytic activity reflected by elevations of PAI-1 [21, 36]. In a previous study, we also found that patients with OSAS presented significantly higher circulating levels of PAI-1, and the difference was even more marked in patients with both OSAS and hypertension [32]. In the current study, treatment with CPAP decrease blood levels of PAI-1.

Among the most important vasoconstrictive substances is endothelin-1, a peptide hormone secreted under the influence of hypoxia [37, 38]. However, the evidence for increased production of vasoconstrictive substances such as endothelin-1 in patients with OSAS is inconsistent. Several studies have reported higher endothelin-1 levels in OSAS patients [25, 39, 40]; however, Grimpen reports conflicting findings [41]. This divergence might be explained by differences in study design. The groups studied by Phillips et al. [39] and Saarelainen and Hasan [40] had more severe disease and thus underwent more severe oxygen desaturations that acted as a trigger for endothelin-1 secretion. Gjørup showed that hypertensive OSAS patients had greater nocturnal and diurnal endothelin-1 plasma levels than healthy controls, suggesting that OSAS does not affect plasma endothelin-1 levels in the absence of coexistent cardiovascular diseases [42, 43].

The inconsistency of the above endothelin-1 levels likely reflects the predominantly abluminal release of endothelin. Using rat models of arterial hypertension, several authors have reported elevated vascular production of endothelin-1, while circulating levels remained similar to controls [44, 45]. This demonstrates that circulating levels of endothelin-1 do not exclude elevated vascular production in OSAS. Our findings indicate that the control of apnoeas through CPAP treatment did not modify initial levels of endothelin.

Certain limitations in the present study need to be taken into consideration. Firstly, the measurements of circulating adhesion molecules were based on the assumption that the number of circulating adhesion molecules reflects the number of cell surface adhesion molecules. Secondly, blood samples were obtained only in the morning, which may have affected random variability because oscillations during the day were not taken into account.

In conclusion, as a follow-up to our previous findings regarding the increased levels of adhesion molecules and PAI-1 associated with OSAS, here we demonstrate that levels of these markers return to normal with long-term CPAP treatment.

\section{Acknowledgments}

This study was supported by a Fondo Investigación Sanitaria grant (01/0634).

\section{References}

1. Young T, Palta M, Dempsey J, Skatrud J, Weber S, Badr S. The occurrence of sleep-disordered breathing among middle-aged adults. N Engl J Med 1993; 328: 1230-5. 
2. Pichel F, Zamarron C, Magan F, Del Campo F, Alvarez-Sala R, Suarez JR. Health-related quality of life in patients with obstructive sleep apnea: effects of long-term positive airway pressure treatment. Respir Med 2004; 98: 968-76.

3. Teran-Santos J, Jimenez-Gomez A, Cordero-Guevara J. The association between sleep apnea and the risk of traffic accidents. Cooperative Group Burgos-Santander. N Engl J Med 1999; 340: 847-51.

4. Wolf J, Narkiewicz K. Hypertension and obstructive sleep apnoea. Arch Med Sci 2009; 5: S330-6.

5. Marin JM, Carrizo SJ, Vicente E, Agusti AG. Long-term cardiovascular outcomes in men with obstructive sleep apnoea-hypopnoea with or without treatment with continuous positive airway pressure: an observational study. Lancet 2005; 365: 1046-53.

6. Durán-Cantolla J, Aizpuru F, Montserrat JM, et al.; Spanish Sleep and Breathing Group. Continuous positive airway pressure as treatment for systemic hypertension in people with obstructive sleep apnoea: randomised controlled trial. BMJ 2010; 24: c5991.

7. Somers VK, Dyken ME, Clary MP, Abboud FM. Sympathetic neural mechanisms in obstructive sleep apnea. J Clin Invest 1995; 96: 1897-904.

8. Bonsignore MR, Parati G, Insalaco G, et al. Baroreflex control of heart rate during sleep in severe obstructive sleep apnoea: effects of acute CPAP. Eur Respir J 2006; 27: 128-35.

9. Dorkova Z, Petrasova D, Molcanyiova A, Popovnakova M, Tkacova R. Effects of continuous positive airway pressure on cardiovascular risk profile in patients with severe obstructive sleep apnea and metabolic syndrome. Chest 2008; 134: 686-92.

10. Schulz R, Mahmoudi S, Hattar K, et al. Enhanced release of superoxide from polymorphonuclear neutrophils in obstructive sleep apnea. Impact of continuous positive airway pressure therapy. Am J Respir Crit Care Med 2000; 162: 566-70.

11. Kanagy NL, Walker BR, Nelin LD. Role of endothelin in intermittent hypoxia-induced hypertension. Hypertension 2001; 37: $511-5$

12. Halcox JP, Donald AE, Ellins E, et al. Endothelial function predicts progression of carotid intima-media thickness. Circulation 2009; 119: 1005-12.

13. Anderson TJ, Uehata A, Gerhard MD, et al. Close relation of endothelial function in the human coronary and peripheral circulations. J Am Coll Cardiol 1995; 26: 1235-41.

14. Nieto FJ, Herrington DM, Redline S, Benjamin EJ, Robbins JA. Sleep apnea and markers of vascular endothelial function in a large community sample of older adults. Am J Respir Crit Care Med 2004; 169: 354-60.

15. Chung S, Yoon IY, Lee CH, Kim JW. The association of nocturnal hypoxemia with arterial stiffness and endothelial dysfunction in male patients with obstructive sleep apnea syndrome. Respiration 2010; 79: 363-9.

16. Ip MS, Tse HF, Lam B, Tsang KW, Lam WK. Endothelial function in obstructive sleep apnea and response to treatment. Am J Respir Crit Care Med 2004; 169: 348-53.

17. Trzepizur W, Gagnadoux F, Abraham P, et al. Microvascular endothelial function in obstructive sleep apnea: impact of continuous positive airway pressure and mandibular advancement. Sleep Med 2009; 10: 746-52.

18. Juhan-Vague I, Alessi MC, Vague P. Thrombogenic and fibrinolytic factors and cardiovascular risk in non-insulindependent diabetes mellitus. Ann Med 1996; 28: 371-80.

19. Jovin IS, Muller-Berghaus G. Interrelationships between the fibrinolytic system and lipoproteins in the pathogen- esis of coronary atherosclerosis. Atherosclerosis 2004; 174: 225-33.

20. Saigo M, Hsue PY, Waters DD. Role of thrombotic and fibrinolytic factors in acute coronary syndromes. Prog Cardiovasc Dis 2004; 46: 524-38.

21. von Kanel R, Dimsdale JE. Hemostatic alterations in patients with obstructive sleep apnea and the implications for cardiovascular disease. Chest 2003; 124: 1956-67.

22. Hlubocká Z, Umnerová V, Heller S, et al. Circulating intercellular cell adhesion molecule-1, endothelin-1 and von Willebrand factor-markers of endothelial dysfunction in uncomplicated essential hypertension: the effect of treatment with ACE inhibitors. J Hum Hypertens 2002; 16 : 557-62.

23. Chin K, Nakamura T, Shimizu K, et al. Effects of nasal continuous positive airway pressure on soluble cell adhesion molecules in patients with obstructive sleep apnea syndrome. Am J Med 2000; 109: 562-7.

24. Lavie L, Kraiczi H, Hefetz A, et al. Plasma vascular endothelial growth factor in sleep apnea syndrome: effects of nasal continuous positive air pressure treatment. Am J Respir Crit Care Med 2002; 165: 1624-8.

25. Zamarrón-Sanz C, Ricoy-Galbaldon J, Gude-Sampedro F, Riveiro-Riveiro A. Plasma levels of vascular endothelial markers in obstructive sleep apnea. Arch Med Res 2006; 37: 552-5.

26. El-Solh AA, Mador MJ, Sikka P, Dhillon RS, Amsterdam D, Grant BJ. Adhesion molecules in patients with coronary artery disease and moderate-to-severe obstructive sleep apnea. Chest 2002; 121: 1541-7.

27. Price DT, Loscalizo J. Celular adhesion molecules and atherogfenesis. Am J Med 1999; 107: 85-97.

28. Ohga E, Nagase T, Tomita T, et al. Increased levels of circulating ICAM-1, VCAM-1, and L-selectin in obstructive sleep apnea syndrome. J Appl Physiol 1999; 87: 10-4.

29. Dyugovskaya L, Lavie P, Lavie L. Increased adhesion molecules expression and production of reactive oxygen species in leukocytes of sleep apnea patients. Am J Respir Crit Care Med 2002; 165: 934-9.

30. von Kanel R, Loredo JS, Powell FL, Adler KA, Dimsdale JE. Short-term isocapnic hypoxia and coagulation activation in patients with sleep apnea. Clin Hemorheol Microcirc 2005; 33: 369-77.

31. Varol E, Ozturk O, Gonca T, et al. Mean platelet volume is increased in patients with severe obstructive sleep apnea. Scand J Clin Lab Invest 2010; 70: 497-502.

32. Zamarron C, Ricoy J, Riveiro A, Gude F. Plasminogen activator inhibitor-1 in obstructive sleep apnea patients with and without hypertension. Lung 2008; 186: 151-6.

33. Ishikawa J, Hoshide S, Eguchi K, et al. Increased low-grade inflammation and plasminogen-activator inhibitor-1 level in nondippers with sleep apnea syndrome. J Hypertens 2008; 26: 1181-7.

34. Shitrit D, Peled N, Shitrit AB, et al. An association between oxygen desaturation and D-dimer in patients with obstructive sleep apnea syndrome. Thromb Haemost 2005; 94: 544-7.

35. von Kanel R, Loredo JS, Ancoli-Israel S, Mills PJ, Natarajan L, Dimsdale JE. Association between polysomnographic measures of disrupted sleep and prothrombotic factors. Chest 2007; 131: 733-9.

36. Kohler M, Pepperell JC, Casadei B, et al. CPAP and measures of cardiovascular risk in males with OSAS. Eur Respir J 2008; 32: $1488-96$.

37. Allahdadi KJ, Duling LC, Walker BR, Kanagy NL. Eucapnic intermittent hypoxia augments endothelin-1 vasoconstriction in rats: role of PKC delta. Am J Physiol Heart Circ Physiol 2008; 294: H920-7. 
38. Belaidi E, Joyeux-Faure $M$, Ribuot $C$, Launois $S H$, Levy $P$, Godin-Ribuot D. Major role for hypoxia inducible factor-1 and the endothelin system in promoting myocardial infarction and hypertension in an animal model of obstructive sleep apnea. J Am Coll Cardiol 2009; 53: 1309-17.

39. Phillips BG, Narkiewicz K, Pesek CA, Haynes WG, Dyken ME, Somers VK. Effects of obstructive sleep apnea on endothelin-1 and blood pressure. J Hypertens 1999; 17: 61-6.

40. Saarelainen S, Hasan J. Circulating endothelin-1 and obstructive sleep apnoea. Eur Respir J 2000; 16: 794-5.

41. Grimpen F, Kanne P, Schulz E, Hagenah G, Hasenfuss G, Andreas $S$. Endothelin-1 plasma levels are not elevated in patients with obstructive sleep apnoea. Eur Respir J 2000; 15: 320-5.

42. Gjørup PH, Sadauskiene L, Wessels J, Nyvad O, Strunge B, Pedersen EB. Abnormally increased endothelin-1 in plasma during the night in obstructive sleep apnea: relation to blood pressure and severity of disease. Am J Hypertens 2007; 20: 44-52.

43. Gjørup PH, Wessels J, Pedersen EB. Abnormally increased nitric oxide synthesis and increased endothelin-1 in plasma in patients with obstructive sleep apnoea. 2008. Scand Clin Lab Invest 2008; 68: 375-85.

44. Pohl U, Busse R. Differential vascular sensitivity to luminally and adventitially applied endothelin-1. J Cardiovasc Pharmacol 1989; 13 Suppl 5: S188-90.

45. Rossi GP, Pitter G. Genetic variation in the endothelin system: do polymorphisms affect the therapeutic strategies? Ann N Y Acad Sci 2006; 1069: 34-50. 